\title{
BROADBAND TIME DOMAIN MODELING OF EARTHQUAKES FROM FRIULI, ITALY
}

\author{
By JOHN CIPAR
}

\begin{abstract}
Short-period (SP) and long-period (LP) seismograms written by the main shock and two principal aftershocks of the 1976 Friuli, Italy, earthquake sequence are modeled in the time domain using synthetic seismograms. The main shock occurred on 6 May $1976\left(20 \mathrm{~h} 00 \mathrm{~m}, M_{S}=6.5\right)$ and both aftershocks on 15 September $1976\left(03 \mathrm{~h} 15 \mathrm{~m}, M_{S}=6.0\right.$ and $\left.09 \mathrm{~h} 21 \mathrm{~m}, M_{s}=5.9\right)$. Source models were determined initially by trial and error and then refined using a waveform inversion program. Two point sources of radiation are required to adequately model the aftershock short-period records. For the $09 \mathrm{~h} 21 \mathrm{~m}$ aftershock, the model derived from short-period records also produces good fits to the longperiod data. The seismic moment of this earthquake is found to be 0.8 to 1.0 $\times 10^{25}$ dyne-cm. The SP model for the $03 \mathrm{~h} 15 \mathrm{~m}$ aftershock, on the other hand, predicts long-period synthetics which do not agree with the observations. In particular, the SP moment $\left(0.37 \times 10^{25}\right.$ dyne-cm) is about $2 \frac{1}{2}$ tımes smaller than the LP moment $\left(1 \times 10^{25}\right.$ dyne-cm). Adding a long-period component to the SP model considerably improves LP waveform and moment agreement. In the case of the main shock, a reasonable fit to the observed SP data is obtained using three point sources of radiation. However, LP synthetics computed using this model do not agree with the observations, and the SP moment $\left(0.65 \times 10^{25}\right.$ dyne-cm) is a small fraction of the LP moment ( 3 to $5 \times 10^{25}$ dyne-cm). Time function durations indicate that the individual events inferred from the SP records are radiated from patches of the fault having radii of 2 to $4 \mathbf{k m}$ and stress drops in the range 35 to 276 bars. In comparison, stress drops estimated from LP data are found to be 12 bars (main shock) and 24 bars $(09 \mathrm{~h} 21 \mathrm{~m}$ aftershock). These observations suggest that the short-period instruments are sensitive to the high-frequency radiation emitted from small, high-stress drop areas on the fault plane whereas the long-period instruments record the overall motion during the earthquake.
\end{abstract}

\section{INTRODUCTION}

Recent years have witnessed considerable advances in understanding earthquake source processes by detailed investigation of body waves. Most studies done to date have concentrated on $P$ and $S$ waves recorded by long-period seismographs. A partial list of contributors includes Wyss and Hanks (1972), Burdick and Mellman (1976), Langston and Butler (1976), Langston (1976, 1978), Ebel et al. (1978), and Cipar (1980).

Less attention has been paid to teleseismic short-period records. This is due, no doubt, to the rather complex appearance of these scismograms resulting from the sensitivity of short-period radiation to the vagaries of the seismic source and propagation medium. Burdick and Mellman (1976) used a long-period-short-period deconvolution technique to obtain a more detailed time function for the Borrego Mountain, California, earthquake. Somerville et al. (1976) used the Savage (1966) source model and an inversion scheme to obtain fault parameters for two shortduration earthquakes. Langston (1976) found that crustal effects were important in time domain modeling of the short-period records of the Koyna, India, earthquake. 
Langston (1978) used short-period observations to fix the hypocentral depth and infer a small amount of down-dip rupture propagation during the 1971 San Fernando earthquake. Ebel (1980) argued for localized high-stress drop in the Borrego Mountain earthquake. Hartzell (1980) modeled the long- and short-period body waves from the 1976 Gazli, USSR, earthquake, finding evidence for upward rupture propagation initiated by massive, localized faulting at the hypocenter. Simultaneous modeling of short- and long-period records led Bache et al. (1980) to a similar conclusion regarding the 1975 Pocatello Valley, Idaho, earthquake. Wyss and Hanks

TABLE 1

Earthquake Parameters

\begin{tabular}{rlccccccc}
\hline No & \multicolumn{1}{c}{ Date } & $\mathrm{h}$ & $\mathrm{m}$ & $\begin{array}{c}\text { Latitude } \\
\left({ }^{\circ} \mathrm{N}\right)\end{array}$ & $\begin{array}{c}\text { Longitude } \\
\left({ }^{\circ} \mathrm{E}\right)\end{array}$ & $\begin{array}{c}\text { Depth } \\
(\mathrm{km})\end{array}$ & $m_{b}$ & $M_{\text {, }}$ \\
\hline 1 & 6 May 1976 & 20 & 00 & 4636 & 13.28 & 9 & 60 & 6.5 \\
42 & 15 September 1976 & 03 & 15 & 4630 & 13.20 & $10 \mathrm{G}$ & 57 & 6.0 \\
46 & 15 September 1976 & 09 & 21 & 46.32 & 13.13 & 17 & 54 & 5.9 \\
\hline
\end{tabular}

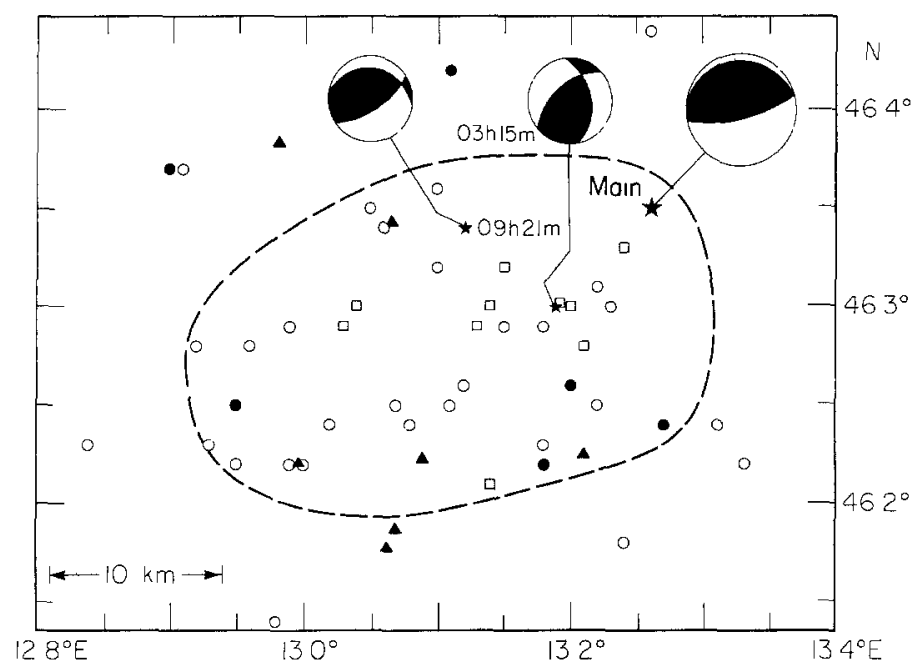

FIG 1. Epicenters of the main shock and larger aftershocks of the Friul earthquake sequence as reported by the ISC. Large star indicates the main shock. Closed circles represent aftershocks which occurred within the first $24 \mathrm{hr}$ and open circles are later aftershocks up to 11 September. Smaller stars are epicenters of the two largest earthquakes on 15 September. Open squares are aftershocks of these events. Lower hemisphere focal mechanısms are shown with compressional quadrants shaded. Heavy dashed line denotes the approximate limit of aftershock concentration Triangles are accelerograph stations

(1972) employed short-period observations to extend their source spectra measurements.

This paper presents an interpretation of the source processes of the main shock and two aftershocks of the 1976 Friuli, Italy, earthquake sequence (Table 1). The three earthquakes occurred in northeastern Italy: the main shock on 6 May 1976 $(20 \mathrm{~h} \mathrm{00m} \mathrm{UTC)} \mathrm{and} \mathrm{both} \mathrm{aftershocks} \mathrm{approximately} 4$ months later, on 15 September $1976(03 \mathrm{~h} 15 \mathrm{~m}$ and $09 \mathrm{~h} 21 \mathrm{~m})$. These aftershocks were the culminating events in a dramatic increase in seismic activity which began on 11 September and were by far the largest aftershocks of the sequence, approaching the main shock in size and 
occurring within a few kilometers of the main shock (Figure 1). These earthquakes are important because of their position on an intracontinental plate boundary and because of the great loss of life and severe damage they caused. Furthermore, they were well-recorded by long- and short-period seismographs and accelerographs. This set of observations, taken over a wide frequency band, allows a detailed picture of the source to be obtained. Cipar (1980) has developed source models for the main shock and largest aftershock $(09 \mathrm{~h} 21 \mathrm{~m})$ based on long-period body and surface wave data. His results showed that the main shock and $09 \mathrm{~h} 21 \mathrm{~m}$ aftershock represented shallow angle thrusting of the Alps over the Friuli Plain. Source depth, seismic moment, and time function duration were found to be $8 \mathrm{~km}, 2.9 \times 10^{25} \mathrm{dyne}-\mathrm{cm}$, and $4.5 \mathrm{sec}$ for the main shock; and $6 \mathrm{~km}, 1.0 \times 10^{25}$ dyne-cm, and $3.5 \mathrm{sec}$ for the aftershock. The fault area which radiated the long-perıod body waves was estimated by comparing the observed records to synthetics computed for finite fault models and were found to be 400 and $100 \mathrm{~km}^{2}$ for the main shock and aftershock, respectively. Surface wave observations at $100-\mathrm{sec}$ period confirm the long-period body

TABLE 2

\begin{tabular}{|c|c|c|c|c|c|c|c|}
\hline \multicolumn{8}{|c|}{ Station Data } \\
\hline Station & $\begin{array}{l}\text { Delta } \\
\text { (deg) }\end{array}$ & $\begin{array}{l}\text { Azimuth } \\
\text { (deg) }\end{array}$ & $\begin{array}{c}\text { Bach } \\
\text { Azımuth } \\
\text { (deg) }\end{array}$ & Station & $\begin{array}{l}\text { Delta } \\
\text { (deg) }\end{array}$ & $\begin{array}{c}\text { Azumuth } \\
\text { (deg) }\end{array}$ & $\begin{array}{c}\overline{\mathrm{Back}} \\
\text { Azumuth } \\
\text { (deg) }\end{array}$ \\
\hline AAE & 43 & 1415 & 3342 & MA & 838 & 415 & 3253 \\
\hline ALQ & 825 & 14 & 3 & MSI & 35.8 & 89.4 & 3010 \\
\hline ATL & 714 & 299.1 & 464 & MSO & 76.3 & 325.8 & 345 \\
\hline BUL & 676 & 164.4 & 348.6 & NAI & 518 & 1494 & 339.4 \\
\hline CAR & 757 & 270.4 & 447 & NDI & 524 & 860 & 308.2 \\
\hline $\mathrm{CHG}$ & 737 & 79.6 & 314.1 & QUE & 443 & 91.9 & 307.0 \\
\hline $\mathrm{COL}$ & 68 & 4 & 140 & SHA & 75.6 & 299.5 & 44.4 \\
\hline DUG & 81.3 & 3213 & 344 & SHI & 34.7 & 104.7 & 3098 \\
\hline GOL & 78.3 & 3164 & 38.3 & SJG & 698 & 2754 & 465 \\
\hline KBS & 327 & 359.6 & 1785 & TRN & 71.7 & 266.4 & 447 \\
\hline KTG & 296 & 3368 & 1259 & WES & 578 & 2994 & 54.5 \\
\hline LON & 79.3 & 330.5 & 29.8 & & & & \\
\hline
\end{tabular}

wave focal mechanism and seismic moment for the main shock. The stress drop was calculated to be 12 bars for the main shock and 24 bars for the aftershock. In this paper, short-period seismograms are modeled in the time domain to obtain a more detailed estimate of the source time function. The short-period models are then tested against the long-period observations to obtain a picture of the source in the period range 1 to $100 \mathrm{sec}$.

\section{Data AND Methods}

A good set of WWSSN long- and short-period records are available for the main shock and both aftershocks, although the long-period $P$ waves for the $03 \mathrm{~h} 15 \mathrm{~m}$ event are obscured in many cases by the coda of an earlier teleseism. Stations used for body and surface wave analysis were chosen based on clarity of recording and absence of long-period noise. Distances and azimuths to each station are listed in Table 2. $P$ - and Rayleigh-wave portions of each seismogram were digitized on an electronic digitizing table and detrended and interpolated by computer. Short- and 
long-period $P$ waves were corrected for instrumental magnification and plotted at a uniform time scale.

Most of the results of this paper were obtained by computing time domain synthetic seismograms and comparing these directly to observed records. The fitting process was done manually, by trial and error, and automatically, using a waveform inversion routine (Mellman, 1978). Synthetics were computed for a point source embedded in a layered medium using either the plane wave approximation to generalized ray theory (Helmberger, 1974; Langston and Helmberger, 1975) or layer matrices (Haskell, 1962). Operators describing instrument response, earth attenuation, and far-field source time history are convolved with the medium response to create synthetics.

The instrument response was calculated using the method described by Hagiwara (1958) for World Wide Standardized Seismograph Network (WWSSN) long- and short-period instruments. A measure of the effective bandwidth of the instrument is the period range over which the response is within a factor of 10 of the peak magnification. Using this criterion, the effective bandwidths of the long-period (peak magnification at $15 \mathrm{sec}$ ) and short-period (peak at $0.6 \mathrm{sec}$ ) instruments are approximately 1 to $100 \mathrm{sec}$ and 0.1 to $2 \mathrm{sec}$, respectively. For earthquakes of the size studied in this paper, long-period records measure primarily the flat portion of the source spectrum whereas short-period instruments sample the high-frequency slope.

Anelastic attenuation is taken into account through the use of a frequency independent $Q$ operator assuming a constant value of $T / Q=1.0 \mathrm{sec}$ (Futterman, 1962). The far-field source time history is represented by a generalized trapezoidal form defined by the rise, top, and fall times (Langston and Helmberger, 1975). Once the shape of the time function is obtained by waveform modeling, it can be interpreted in the light of realistic models of seismic sources (e.g., Savage, 1966). After correcting for geometrical spreading, the absolute amplitude of the waveforms are scaled by the seismic moment.

\section{Modeling Short-Period Records}

Modeling the short-period $P$-wave seismograms of the three Friuli earthquakes proceeded in two distinct phases. The initial part of the work involved a lengthy attempt to model the records by trial and error. Reasonable models were obtained for each earthquake and were used as starting models for a waveform inversion routine (Mellman, 1978). The primary advantage of the inversion program is that it is a fast, unbiased method of assessing the agreement between observed and synthetic records for a portion of the model space around the starting model. The program attempts to find a path through the model space along which the discrepancies between observed and synthetic records decrease. The inversion procedure was stopped when there was little or no further improvement in the cross-correlation, $N_{\imath}$, of the synthetic and observed seismograms (Burdick and Mellman, 1976). Overall goodness-of-fit for each model was computed using the formula

$$
\sum_{\iota}\left\{\left(1-N_{\imath}\right) / w_{\iota}\right\}^{2}
$$

where $w_{\iota}(\geqq 1)$ is the weight of each station with $w_{\imath}=1.0$ implying full weight. Best fitting models are those with the lowest overall goodness-of-fit whereas the best stations have the highest correlation coefficients. These quantities are given in Table 7 for the starting and final models for the 15 September aftershocks. The 
stations used in the inversion runs are marked by asterisks after the station abbreviation in Figures 3, 7, and 9. There is no guarantee of uniqueness in this procedure, but the source models thus obtained are reasonable in all cases.

All inversion runs were made using three rays $(P, p P, s P)$ in a half-space, while the synthetics presented below (Figures 3, 4, 7, 8, 9) were computed with the Angenheister (1972) crustal model (Table 3; see Cipar, 1980, for a discussion). The calculations were done using the same source time function for each ray, irrespective of wave type or take-off angle. Source models derived from inverting short-period

TABLE 3

\begin{tabular}{cccccc}
\multicolumn{5}{c}{ Crustal Models } \\
\hline \multirow{3}{*}{ Lajer } & $\begin{array}{c}\text { P.Wave } \\
\text { Velocity }\end{array}$ & $\begin{array}{c}\text { S.Wave } \\
\text { Velocity }\end{array}$ & $\begin{array}{c}\text { Density } \\
(\mathrm{gm} / \mathrm{cm})\end{array}$ & $\begin{array}{c}\text { Thichness } \\
(\mathrm{km})\end{array}$ & $\begin{array}{c}\text { Depth } \\
(\mathbf{k m})\end{array}$ \\
\hline
\end{tabular}

Angenheister et al (1972)

$\begin{array}{rrrrrr}1 & 6.0 & 347 & 2.60 & 220 & 0 . \dot{0} \\ 2 & 62 & 358 & 266 & 24 & 220 \\ 3 & 6.4 & 3.70 & 272 & 12 & 244 \\ 4 & 66 & 381 & 2.78 & 2.4 & 256 \\ 5 & 68 & 393 & 2.84 & 6.0 & 280 \\ 6 & 70 & 405 & 290 & 80 & 340 \\ 7 & 80 & 462 & 320 & - & 420\end{array}$

Half-space

I $\quad 60 \quad 3.50 \quad 278 \quad-\quad-\quad-$

TABLE 4

09h $21 \mathrm{~m}$ Source Models

\begin{tabular}{|c|c|c|c|c|c|c|c|c|c|}
\hline & $\begin{array}{l}\text { Strike } \\
\text { (deg) }\end{array}$ & $\begin{array}{l}\text { Dip } \\
\text { (deg) }\end{array}$ & $\begin{array}{l}\text { Rake } \\
\text { (deg) }\end{array}$ & $\begin{array}{l}\text { Depth } \\
(\mathrm{km})\end{array}$ & $\begin{array}{c}M_{0} \\
\left(10^{25} \text { dyne-cm) }\right.\end{array}$ & $\begin{array}{l}\text { Time } \\
\text { Lag } \\
\text { (sec) }\end{array}$ & $\begin{array}{l}\text { Ruse } \\
\text { (sec) }\end{array}$ & $\begin{array}{l}\text { Top } \\
(\mathrm{sec})\end{array}$ & $\begin{array}{l}\text { Fall } \\
(\mathrm{sec})\end{array}$ \\
\hline Cıpar (1980) & 56 & 67 & 70 & 60 & 104 & 00 & 10 & 15 & 1.0 \\
\hline \multicolumn{10}{|c|}{ Starting model SP35 } \\
\hline 1st & 56 & 67 & 70 & 6.75 & 017 & 0.0 & 05 & 1.0 & 10 \\
\hline 2nd & 56 & 67 & 70 & 675 & 068 & 15 & 05 & 10 & 10 \\
\hline \multicolumn{10}{|c|}{ Final model SP53 } \\
\hline 1 st & 56 & 67 & 70 & 75 & 0.18 & 00 & 0.72 & 082 & 010 \\
\hline 2nd & 56 & 67 & 70 & 59 & 059 & 13 & 115 & 00 & 115 \\
\hline
\end{tabular}

data were tested against long-period seismograms with varying success as will be shown below.

09h $21 \mathrm{~m}$ Aftershock. The earthquake of 15 September 1976 at $09 \mathrm{~h} 21 \mathrm{~m}$ will be discussed first because the interpretation of its source properties is the most straightforward. The long-period records for this earthquake were studied by Cipar (1980) who obtained the thrust mechanism shown in Figure 1. Geological considerations suggest that the northward-dipping plane is the fault plane, indicating southward thrusting of the Alps over the Friuli Plain. Focal depth, time function duration, and seismic moment were found to be $6 \mathrm{~km}, 3.5 \mathrm{sec}$, and $1.04 \times 10^{25}$ dynecm respectively (Tle 4). 
In the trial and error stage of modeling the short-period records, considerable attention was paid to three stations in the western United States: GOL, ALQ, and DUG. Examining the observed seismograms in the upper left corner of Figure 3, note that the overall waveforms at these stations are quite similar. This suggests that the records are dominated by source properties and crustal structure in the focal region and that receiver crustal structure has only a minor role in shaping the waveforms.

From early modeling efforts, it soon became apparent that the long-period source model of Cipar (1980) would not fit the short-period seismograms and that two sources, a small event followed by a larger one, were necessary to fit the western U.S. records. After numerous attempts, a model called SP35 (Table 4) was found which did reasonably well in predicting the seismograms at GOL, ALQ, and DUG, but not so well for other stations (AAE and GOL are shown in Figure 2). Next, SP35 was used as a starting model for the inversion program. A number of runs were made, each inverting for different combinations of the parameters listed in Table 4. Model SP53 was adopted as the final model, when, after 18 iterations, the inversion

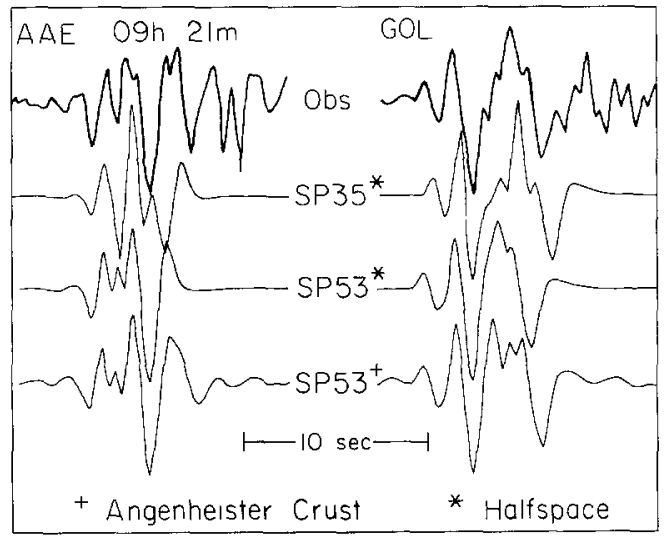

FIG. 2 Comparison of observed seismograms (heavy line) of the $09 \mathrm{~h} 21 \mathrm{~m}$ aftershock recorded at AAE and GOL to synthetics (light line) computed for models SP35 (half-space) and SP53 (half-space and Angenheister crustal model).

program could not make any further improvement to the fit. As can be seen in Table 4, the major differences between SP35 and SP53 are in the depths and time functions of the two sources. There seems to be no azimuthal variation in the relative timing of the sources, suggesting that both are very close together on the fault plane. Results of several inversion runs indicate that the mechanisms of both events are similar. Note the considerable improvement in the fit to station AAE (Figure 2). A comparison of SP53 computed for the half-space and Angenheister et al. (1972) crustal model (Table 3 ) is also shown in Figure 2. There is little difference in the first 4 to $5 \mathrm{sec}$ of record, but the crust does noticeably affect the latter portion. Overall, the Angenheister crustal model improves the fit between observed and synthetic seismograms compared to the half-space case. At most stations, the agreement between observed records and synthetics is quite good (Figure 3, Table 7). Using SP53 to compute long-period seismograms also yields good agreement with the observed data (Figure 4). Even such elusive features as the shoulder on the upswing at stations AAE, NAI, and SHI are reproduced in the long-period synthetics. 


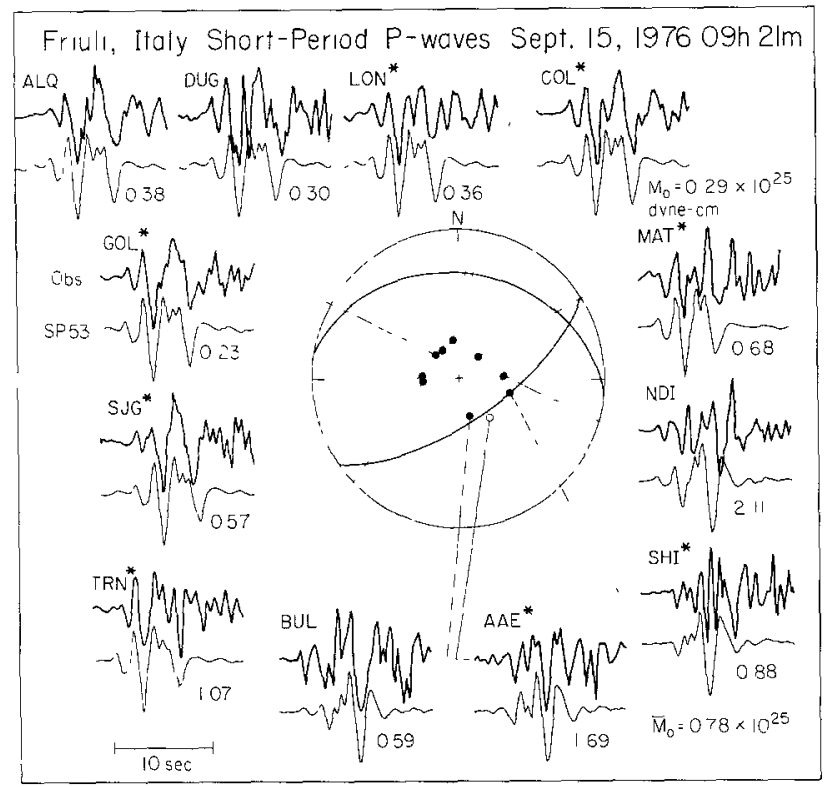

FIG 3 Observed short-period seismograms (heavy line) of the $09 \mathrm{~h} 21 \mathrm{~m}$ aftershock compared to synthetics (light line) computed for model SP53 (Table 4) in the Angenheister et al. (1972) crustal model (Table 3). Numbers below each synthetıc are the seismic moments; the average seismic moment $\left(M_{0}\right)$ is $078 \times 10^{25}$ dyne-cm Asterisks after station abbreviatıons indicate stations used in the inversion program

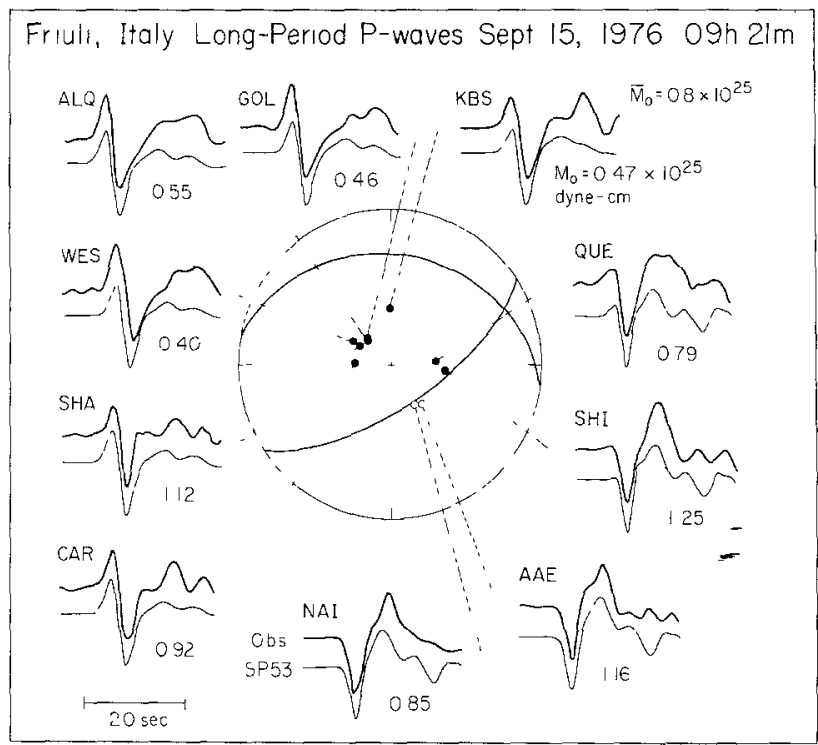

Frg. 4 Observed long-period seismograms (heavy line) of the $09 \mathrm{~h} 21 \mathrm{~m}$ aftershock compared to synthetics (light line) computed for model SP53 (Table 4) in the Angenheister et al (1972) crustal model (Table 3). Numbers below each synthetic are the seismic moment; the average moment is $08 \times 10^{25}$ dyne-cm

The average seismic moment derived from the short-period $P$ waves is $0.78 \times 10^{25}$ dyne-cm, in excellent agreement with the value of $0.8 \times 10^{25}$ dyne-cm obtained from long-period body waves. 
It is of interest to compare the model derived from short-period data, SP53, to the model derived solely from long-period observations by Cipar (1980). Both models produce long-period synthetic seismograms which are very similar, yet SP53 is the more adequate model in that it also correctly predicts the short-period records. The source depths and focal mechanisms for both models are similar; it is the far-field source time functions which differ. The total duration of both time functions, the parameter which controls the long-period waveforms, is also the same $(3.5 \mathrm{sec})$ but the rather complicated structure of the SP53 time function is necessary to explain the short-period records. Note that the seismic moment of SP53 $\left(0.8 \times 10^{25}\right.$ dyne$\mathrm{cm})$ is in reasonable agreement with the value obtained by Cipar $(1980)\left(1 \times 10^{25}\right.$ dyne-cm).

An estimate of the moment for the $09 \mathrm{~h} 21 \mathrm{~m}$ earthquake was also made from the spectral density of 50-sec Rayleigh waves equalized to a distance of $90^{\circ}$. The filled circles of Figure 5 show the observed spectral density at $50 \mathrm{sec}$ for the records

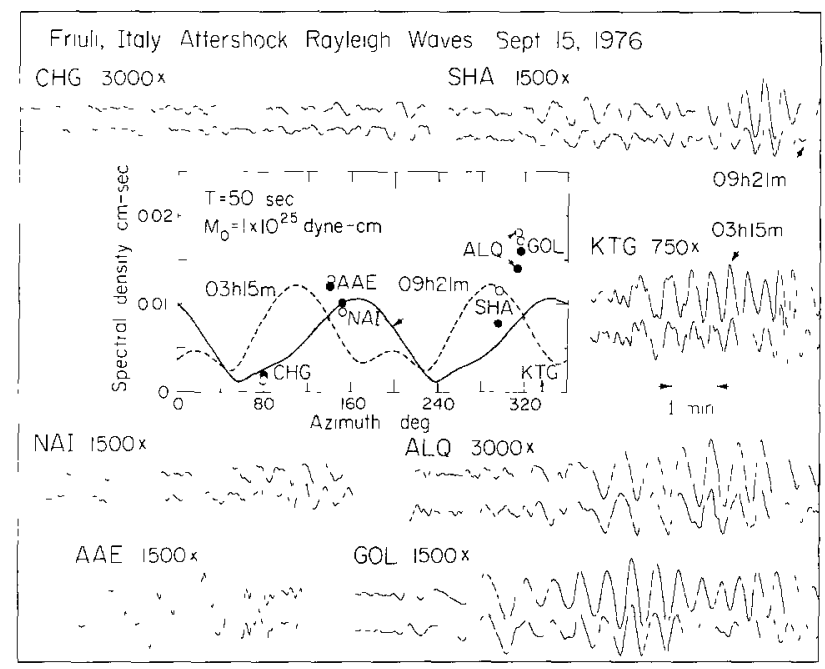

FIg 5 Rayleigh-wave observations of the $03 \mathrm{~h} 15 \mathrm{~m}$ aftershock (upper trace for each station) and the $09 \mathrm{~h} 21 \mathrm{~m}$ shock (lower trace) are compared for a number of WWSSN stations. Numbers after station abbreviation indicate long-period instrument magnification. Inset shows the observed spectral density at 50 -sec period (points) versus theoretical calculations (lines) Filled points and solid lines are for the earthquake of $09 \mathrm{~h} 21 \mathrm{~m}$, open curcles and broken lines are for the $03 \mathrm{~h} 15 \mathrm{~m}$ shock Spectral data are equalized to $90^{\circ}$ and theoretical calculations made assuming a moment of $1 \times 10^{25}$ dyne-cm

shown. The solid line is the theoretical radiation pattern computed from the tables of Ben Menahem et al. (1970) for a source at 10-km depth in their continental structure and having the mechanism shown in Figure 1. The moment inferred from these calculations is 1 to $1.5 \times 10^{25}$ dyne-cm, in reasonable agreement with the estimates made from body waves. These results show that the source spectrum is nearly flat in the period range 0.5 to $50 \mathrm{sec}$.

$03 \mathrm{~h} 15 \mathrm{~m}$ Aftershock. We now turn to a discussion of the aftershock at $03 \mathrm{~h} 15 \mathrm{~m}$ on 15 September. The focal mechanism (Figure 1) is quite different from those of the main shock and 09h $21 \mathrm{~m}$ aftershock. The nodal lines strike north and northeast instead of east-west as for the other events and the mechanism exhibits much more strike-slip character.

The body waves for this earthquake are also somewhat anomalous in that the amplitudes of long-period $P$ waves are considerably smaller than those of the $09 \mathrm{~h}$ 
$21 \mathrm{~m}$ shock whereas the short-period $P$ waves for both earthquakes are comparable in amplitude. These characteristics are illustrated in Figure 6 which shows observed long- and short-period $P$ waves for both aftershocks recorded at GOL and CAR and Rayleigh waves of GOL. Note that for both earthquakes, the GOL short-period $P$ waves have almost the same amplitude, whereas the long-period $P$ wave of the $09 \mathrm{~h}$ $21 \mathrm{~m}$ event is about $2 \frac{1}{2}$ times larger than the long-period $P$ of the $03 \mathrm{~h} 15 \mathrm{~m}$ aftershock. A similar difference in amplitude is seen for the long-period $P$ waves recorded at CAR. On the other hand the Rayleigh waves recorded at GOL are nearly equal in amplitude, especially at longer periods. Examining Figure 5, note that the $P$-wave focal mechanisms (Figure 1) predict almost identical Rayleigh wave amplitude at GOL (solid line is $09 \mathrm{~h} 21 \mathrm{~m}$, broken line is $03 \mathrm{~h} 15 \mathrm{~m}$ ). This implies that the seismic moments of the two earthquakes are nearly equal. The remainder of this section will be concerned with explaining these anomalies.

A number of preliminary source models were made in order to gain a feeling for the nature of the short-period records. As in the case of the $09 \mathrm{~h} 21 \mathrm{~m}$ event, it soon

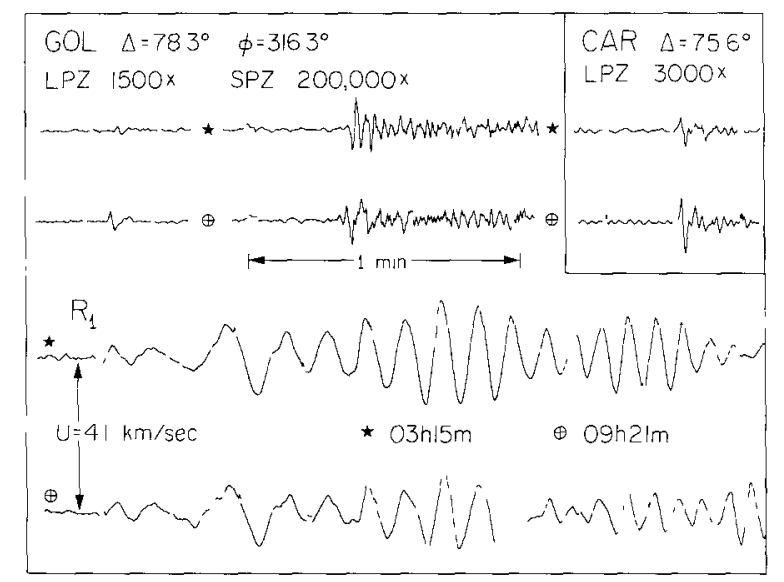

FIG 6 Comparison of observed short- and long-period $P$ waves and Rayleigh waves for the $03 \mathrm{~h} 15 \mathrm{~m}$ (traces denoted by stars) and $09 \mathrm{~h} 21 \mathrm{~m}$ (denoted by circle with cross) aftershocks at GOL and CAR (inset) Numbers after instrument abbreviations are peak magnifications Minute marks are indicated on longperiod records along with group velocity of $4.1 \mathrm{~km} / \mathrm{sec}$ on the Rayleigh wave traces.

became apparent that two sources were necessary to account for the observed records. A rather successful model, SP25, was found by trial-and-error (Table 5) and used as a starting model for the waveform inversion program. After 10 iterations, the program could not significantly improve the fit, and the procedure was stopped. The final model, SP27, is given in Table 5 and a comparison of observed records to synthetics computed for SP27 in the Angenheister crust is shown in Figure 7. The agreement between observed and synthetic is quite good for the first 5 to $7 \mathrm{sec}$ of record for most stations.

The right side of Figure 7 shows observed long-period records compared to longperiod synthetics computed using SP27. As can be seen, there is considerable discrepancy in phase and relative amplitude of the waveforms. In particular, the "glitch" on the downswing of GOL and ALQ is not found in the observed seismograms, and the first upswing at AAE is much too large on the synthetic. Also, the seismic moment computed for the short-period records $\left(0.37 \times 10^{25}\right.$ dyne-cm $)$ is about $2 \frac{1}{2}$ times smaller than the amount inferred from long-period body waves $(1.05$ 
$\times 10^{25}$ dyne-cm). It appears that the short-period instrument has recorded only a fraction of the total radiation of the earthquake.

A closer examination of the Rayleigh data presented in Figure 5 suggests a way to improve the fit to the long-period body waves. Note that at each station, the Rayleigh waves written by both earthquakes are very similar in phase and amplitude, especially the long-period portion of the wave train. Bearing this out, the spectral density determinations at 50 -sec period are quite consistent at each station. The

TABLE 5

03h $15 \mathrm{~m}$ Source Models

\begin{tabular}{|c|c|c|c|c|c|c|c|c|c|}
\hline & $\begin{array}{l}\text { Strike } \\
\text { (deg) }\end{array}$ & $\begin{array}{l}\text { Dip } \\
\text { (deg) }\end{array}$ & $\begin{array}{l}\text { Rake } \\
\text { (deg) }\end{array}$ & $\begin{array}{c}\text { Depth } \\
(\mathrm{km})\end{array}$ & $\begin{array}{c}M_{11} \\
\left(10^{25} \text { dyne-cm) }\right.\end{array}$ & $\begin{array}{c}\text { Tume } \\
\text { Lag } \\
\text { (sec) }\end{array}$ & $\begin{array}{l}\text { Rise } \\
(\mathrm{sec})\end{array}$ & $\begin{array}{l}\text { Top } \\
(\mathrm{sec})\end{array}$ & $\begin{array}{l}\text { Fall } \\
\text { (sec) }\end{array}$ \\
\hline \multicolumn{10}{|c|}{ Startıng model SP25 } \\
\hline 1st & 230 & 60 & 133 & 4.5 & 0.25 & 0.0 & 08 & 0.2 & 05 \\
\hline 2 nd & 230 & 60 & 133 & 45 & 0.12 & 25 & 0.5 & 03 & 05 \\
\hline \multicolumn{10}{|l|}{ Final model SP27 } \\
\hline 1st & 230 & 60 & 133 & 3.77 & 024 & 0.0 & 0.92 & 0.0 & 084 \\
\hline 2nd & 230 & 60 & 133 & 4.23 & 0.12 & 21 & 0.48 & 078 & 026 \\
\hline SP30 LP source & 56 & 67 & 70 & 4.0 & 030 & 00 & 1.0 & 20 & 10 \\
\hline
\end{tabular}

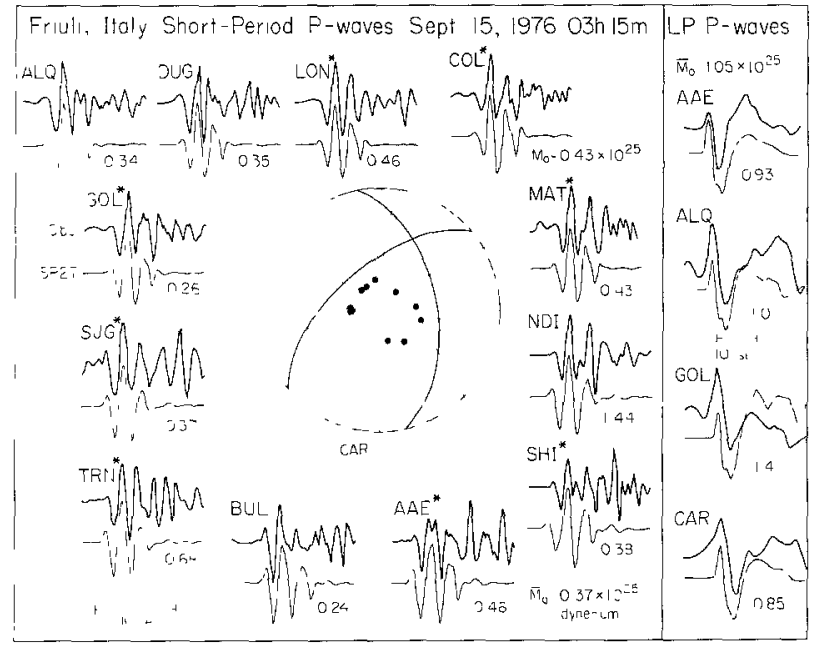

Fig 7 Observed seismograms (heavy line) of the $03 \mathrm{~h} 15 \mathrm{~m}$ earthquake compared to synthetics (light line) computed for model SP27 (Table 5) in the Angenheister et al. (1972) crustal model (Table 3). Numbers below each synthetic are the selsmic moments. Asterısks after the station abbreviations undicate that the station was used in the inversion program. Left side of the diagram shows the short-period data, right side, the long-period. Note the change of time scale. Average moments for both data sets are indicated.

available Rayleigh wave data do not allow an unambiguous determination of the mechanism, although the solution of the $09 \mathrm{~h} 21 \mathrm{~m}$ event seems to be favored. These observations suggest that the surface waves for both shocks were radiated by sources with similar mechanisms and seismic moments (about $1 \times 10^{25}$ dyne-cm).

The long-period body waves also suggest that the mechanism of the two aftershocks are similar. In Figure 6, note that the waveforms recorded at CAR are quite 
similar. Comparing Figures 4 and 7, one can see that except for the initial upswing, the $P$ waves recorded at AAE also look quite similar. These observations suggest that although $P$-wave first motions for the $03 \mathrm{~h} 15 \mathrm{~m}$ event give the mechanism shown in Figure 1, the complete body waveforms and the surface waves are more consistent with a mechanism like that of the $09 \mathrm{~h} 21 \mathrm{~m}$ aftershock (Figure 1).

Taking the above observations into account, several trials were made to fit the long- and short-period records simultaneously by adding a long-period component to model SP27. The mechanism of the $09 \mathrm{~h} 21 \mathrm{~m}$ event was adopted as the mechanism for the long-period component in order to fit the overall shape of the long-period body waves and the surface wave radiation pattern. A plausible model, SP30, is shown in Figure 8 and Table 5. Comparing Figure 8 to Figure 7, note that there is considerable improvement in the long-period fits. The short-period component (SP27) was not readjusted for model SP30 and thus the quality of fit for the short-

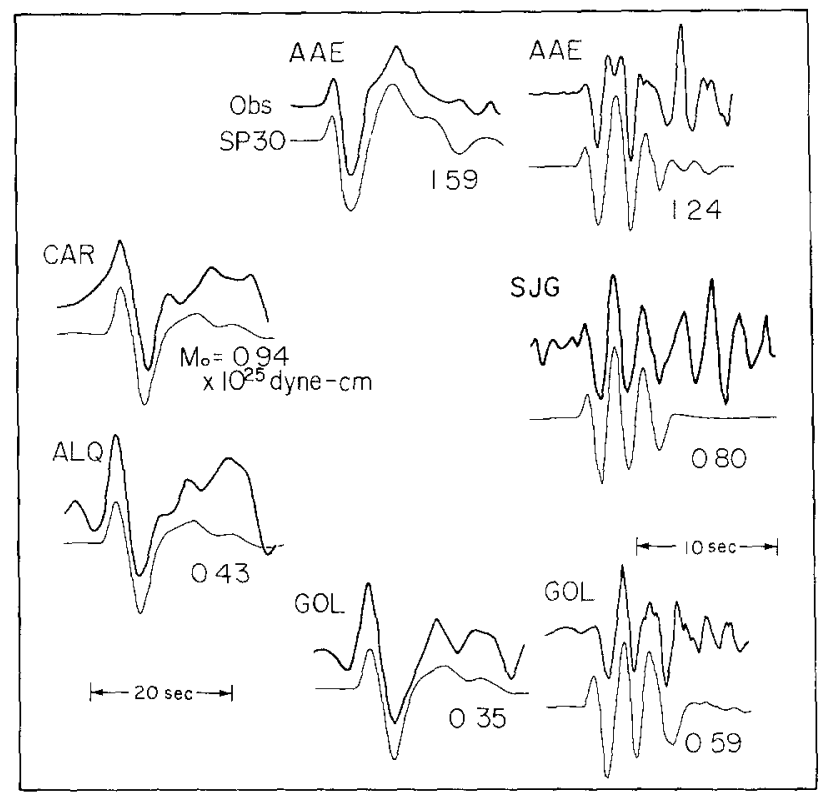

Fig. 8. Observed seismograms (heavy line) of the $03 \mathrm{~h} 15 \mathrm{~m}$ earthquake compared to synthetics (light line) computed for model SP30 (Table 5 and text) in the Angenheister et al. (1972) crustal model, except station SJG which is calculated for a half-space. Numbers under each synthetic indicate the seismic moment. Long-period data are on the left, representative short-period data are on the right. Note change of time scale.

period records is slightly diminished. The average seismic moments for the longperiod $\left(0.83 \times 10^{25}\right.$ dyne-cm) and short-period $\left(0.99 \times 10^{25}\right.$ dyne-cm) data are in good agreement with each other and with the surface wave moment $\left(1\right.$ to $1.5 \times 10^{25}$ dyne-cm). Model SP30 preserves the observed long-period first motions, in particular note station AAE. However, the long-period source, by itself, predicts the wrong polarity at AAE (see Figure 4). The long- and short-period components of model SP30 are necessary to fit the complete data set for the $03 \mathrm{~h} 15 \mathrm{~m}$ aftershock.

Main shock. Compared to the records of the aftershocks, the short-period seismograms written by the 6 May 1976 main shock are quite complex. It is interesting to note (Figure 9) that the records radiated in the $P$-wave loop direction (GOL, MSO, KTG, MAT) are quite similar in appearance, suggesting that receiver crustal 
structure has relatively little effect on $P$ waveforms and that the principal influences are source properties and crustal structure.

The now familiar procedure was repeated for the main shock: a number of trialand-error models were constructed until a suitable starting model was found for use in the inversion program. The forward problem for the main shock was time-

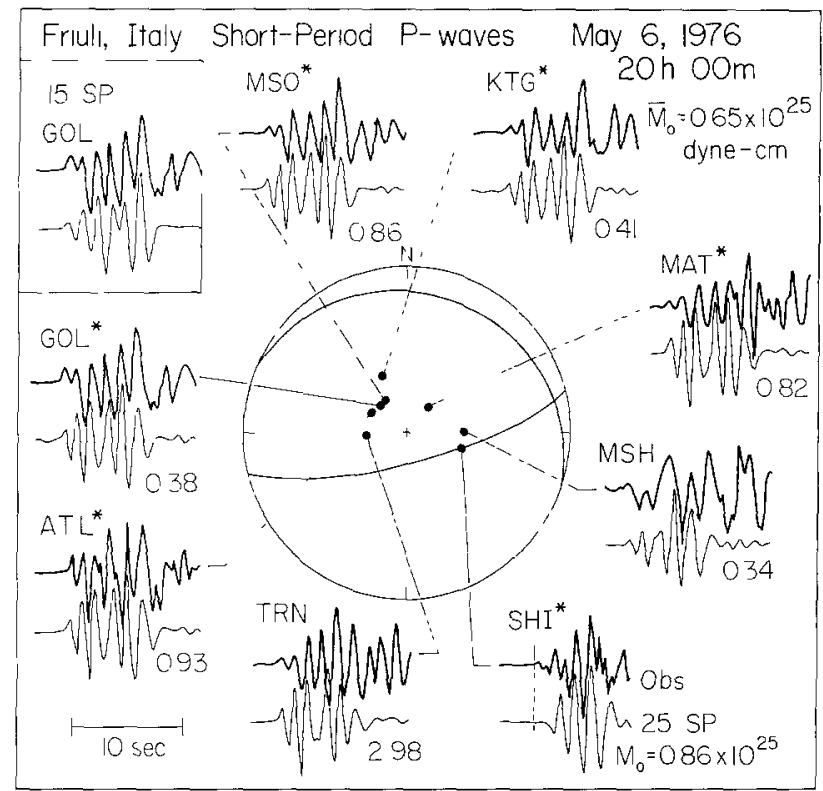

FIG 9. Observed short-period $P$ waves for the mam shock (heavy line) compared to synthetics (light line) computed for model 25SP (Table 6) using the Angenhesster et al. (1972) crustal model (Table 3) Numbers below each synthetic indicate the seismic moment at that station, average moment is $065 \times$ $10^{25}$ dyne-cm Asterisks after the station abbreviation indicate that the station was used in the inversion program The synthetic for GOL for the starting inversion model, 15SP, is shown in the inset at upper left.

TABLE 6

MaIn Shock Source Models

\begin{tabular}{|c|c|c|c|c|c|c|c|c|c|}
\hline & $\begin{array}{l}\text { Strike } \\
\text { (deg) }\end{array}$ & $\begin{array}{c}\text { Dip } \\
\text { (deg) }\end{array}$ & $\begin{array}{l}\text { Rake } \\
\text { (deg) }\end{array}$ & $\begin{array}{l}\text { Depth } \\
(\mathrm{km})\end{array}$ & $\begin{array}{c}M_{u} \\
\left(10^{2} \cdot d y \text { e-cm }\right)\end{array}$ & $\begin{array}{c}\text { Time } \\
\text { Lag } \\
(\mathrm{sec})\end{array}$ & $\begin{array}{l}\text { Ruse } \\
\text { (sec) }\end{array}$ & $\begin{array}{l}\text { Top } \\
\text { (sec) }\end{array}$ & $\begin{array}{l}\text { Fall } \\
\text { (sec) }\end{array}$ \\
\hline Cipar (1980) & 76 & 75 & 80 & 80 & 2.9 & - & 1.0 & 25 & 1.0 \\
\hline \multicolumn{10}{|c|}{ Startıng model I5SP } \\
\hline $1 \mathrm{st}$ & 76 & 75 & 80 & 80 & 014 & - & 0.7 & 0.0 & 0.7 \\
\hline 2nd & 76 & 75 & 80 & 8.0 & 0.29 & 1.4 & 0.7 & 0.0 & 0.7 \\
\hline $3 \mathrm{rd}$ & 76 & 75 & 80 & 80 & 0.57 & 2.8 & 07 & 0.0 & 0.7 \\
\hline \multicolumn{10}{|c|}{ Final model 25SP } \\
\hline $1 \mathrm{st}$ & 76 & 75 & 80 & 80 & 012 & - & 05 & 0.0 & 05 \\
\hline $2 n d$ & 76 & 75 & 80 & 8.0 & 0.27 & 1.15 & 067 & 0.0 & 035 \\
\hline 3rd & 76 & 75 & 80 & 8.0 & 03 & 2.25 & 0.72 & 00 & 0.94 \\
\hline
\end{tabular}

consuming since it became apparent that to fit the waveforms, three or four point sources were required. With up to 11 parameters for each source, investigating the model space for a three source model becomes impossible to do manually. Model 15SP (Table 6) was found to reproduce the salient features of the GOL record, in particular, the number, timing, and to a lesser extent, relative amplitude of the main 
pulses present on the seismogram. The observed record and synthetic are shown in the upper left corner of Figure 9. The inversion program was used to fine tune the parameters of the later, larger sources. The parameters of the first source were then refined by trial and error, keeping the other sources unchanged. The result is model 25SP (Table 6 and Figure 9). While this model is not completely successful in fitting the main shock short-period records, the synthetics do reproduce the number and relative timing of the pulses observed on the real seismograms.

It is instructive to examine several stations in which the model does not work so well. Since the original model was made to fit the GOL records as was the final finetuning, seismograms at other azimuths would be expected to have the greatest discrepancies. For instance, the observed record at SHI begins too early relative to the synthetic. In preliminary models, the relative timing between sources (time lag in Table 6) was greater, causing the synthetic to be stretched in time, producing a better fit at SHI. In order to improve the fit at GOL, these original time lags were reduced by $0.46 \mathrm{sec}$; the dashed line in Figure 9 indicates the discrepancy. A reasonable explanation for this effect is that the sources are not at the same location

TABLE 7

\begin{tabular}{|c|c|c|c|c|}
\hline \multirow{2}{*}{ Station } & \multicolumn{2}{|c|}{$09 \mathrm{~h} 21 \mathrm{~m}$} & \multicolumn{2}{|c|}{$03 \mathrm{~h} 15 \mathrm{~m}$} \\
\hline & $\mathrm{SP} 35$ & SP53 & SP25 & SP27 \\
\hline $\mathrm{AAE}$ & 0.571 & $0759^{*}$ & 0.691 & 0658 \\
\hline $\mathrm{COL}$ & 0443 & 0842 & 0812 & 0.870 \\
\hline GOL & 0553 & 0806 & 0825 & 0875 \\
\hline LON & 0327 & 0845 & 0.817 & 0.923 \\
\hline MAT & 0.491 & 0.557 & 0858 & 0840 \\
\hline SHI & 0383 & $0509^{*}$ & 0469 & 0585 \\
\hline SJG & 0341 & 0743 & 0.747 & 0930 \\
\hline TRN & 0463 & 0770 & 0502 & 0.744 \\
\hline Overall & 2.509 & 0404 & 0809 & 0432 \\
\hline
\end{tabular}

on the fault plane (as is assumed in the calculation) but are at different geographical positions causing different time lags at each station. Considering that the aftershock zone and presumably fault area is roughly $30 \mathrm{~km}$ by $15 \mathrm{~km}$, in good agreement with the area which radiated the long-period body waves (Cipar, 1980), it is not surprising that each point source is in a different part of the fault plane.

The moment estimated from short-period records is about $0.65 \times 10^{25}$ dyne-cm compared to $2.9 \times 10^{25}$ dyne-cm determined from long-period body waves (Cipar, 1980). In addition, the agreement between the long-period synthetics computed for model $25 \mathrm{SP}$ and the observed data is poorer compared to that obtained by Cipar (1980). As in the case of the $03 \mathrm{~h} 15 \mathrm{~m}$ aftershock, it appears that the short-period instruments have recorded only a portion of the energy radiated by the earthquake.

\section{Discussion}

A comparison of the time functions of each earthquake is shown in Figure 10. The time function of each short-period event is shown as a solid line and the dashed lines represent the long-period time functions found by Cipar (1980) for the main 
shock and $09 \mathrm{~h} 21 \mathrm{~m}$ aftershock and the inferred "long-period" source for the $03 \mathrm{~h}$ $15 \mathrm{~m}$ aftershock. Each individual time function is drawn in such a way that the area under the curve is proportional to seismic moment. All three earthquakes are drawn to a common time and moment scale. Note that the moment of the short-period events in each case amounts to only a fraction of the moment inferred from the long-period observations. It is worth emphasizing that all the synthetic calculations were done assuming a $T / Q$ ratio of $1.0 \mathrm{sec}$. The good agreement is moment and waveform for long- and short-period data for the $09 \mathrm{~h} 21 \mathrm{~m}$ event suggests that the source, and not a propagation effect, is responsible for the long-period-short-period moment discrepancy observed for the other earthquakes.

Following the procedure outlined by Ebel et al. (1978), an estimate can be made of the radius of a circular fault which radiates the far-field time function. Total
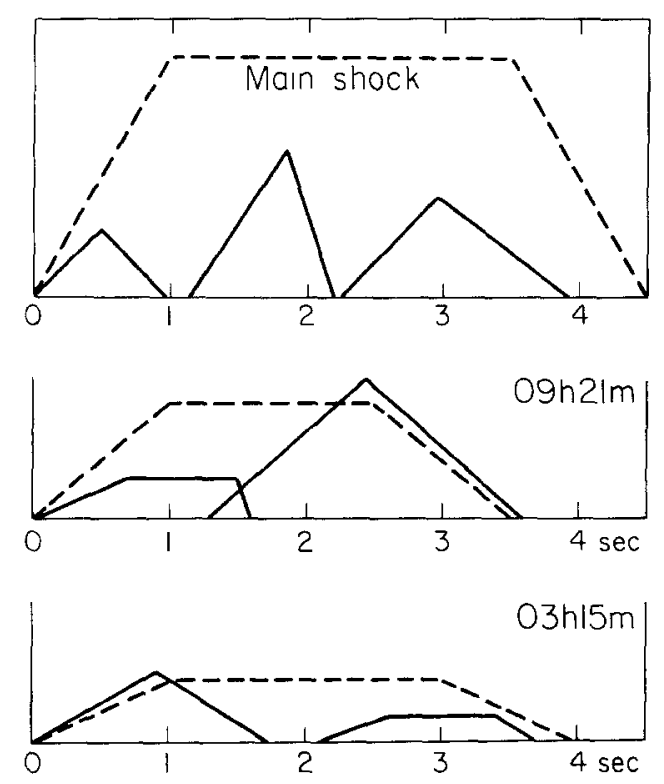

Fig 10 Comparison of observed far-field time functions. Areas under the time functions are scaled to the seismic moment (Table 8) of each event Note tume scale in seconds Solid lines represent the time functions derived from modeling short-period records. Dashed lines are the tume functions found by Cipar (1980) for the main shock and $09 \mathrm{~h} 21 \mathrm{~m}$ aftershock and the long-penod source for the $03 \mathrm{~h} 15 \mathrm{~m}$ earthquake (see text).

duration, $t_{c}$, is the sum of the rise time (first term) plus the rupture time (last two terms)

$$
t_{c}=16 a / 7 \pi \beta+a / V+(a / \alpha) \sin \theta
$$

where $a$ is the radius of a circular fault, $V$ is the rupture velocity, $\alpha$ and $\beta$ are the $P$ and $S$-wave velocities in the source region, and $\theta$ is the angle between the normal to the fault plane and the ray take-off angle. Chung (1978) discusses the derivation of this expression; Geller (1976) derives the form of the rise time term. $t_{c}$ is a measured quantity found by summing the rise, top, and fall times of the source time function. Assuming values for $\alpha(=6.0 \mathrm{~km} / \mathrm{sec}), \beta(=3.5 \mathrm{~km} / \mathrm{sec})$, and $V(=3.0 \mathrm{~km} / \mathrm{sec})$ allows the circular fault radius, $a$, to be calculated. For the $09 \mathrm{~h} 21 \mathrm{~m}$ aftershock and the 
main shock, the inferred fault planes dip gently northward $\left(15^{\circ}\right.$ to $\left.30^{\circ}\right)$; thus the normal to the fault plane is nearly vertical. 'Likewise, the take-off angles to the observing stations are in the range $20^{\circ}$ to $40^{\circ}$ from the downward vertical; hence $\theta$ is small (set to $30^{\circ}$ for the calculations). For the $03 \mathrm{~h} 15 \mathrm{~m}$ earthquake, the nodal planes dip at a much steeper angle and it is unclear which plane is the fault plane. For this earthquake, $\theta$ was arbitrarily set at $45^{\circ}$. The expression for seismic moment (a measured quantity), $M_{0}=\mu D_{0} S$, where $S$ is the fault area ( $=\pi a^{2}$ ), allows calculation of the average dislocation $\left(D_{0}\right)$ assuming a value for the rigidity $(\mu=3$ $\times 10^{11}$ dyne $\left./ \mathrm{cm}^{2}\right)$. The stress drop for a circular fault, $\Delta \sigma=(7 \pi / 16) \mu D_{0} / a$, can then be estimated (Kanamori and Anderson, 1975). These quantities, calculated for each earthquake, are listed in Table 8.

TABLE 8

Source Parameters

\begin{tabular}{|c|c|c|c|c|c|}
\hline $\begin{array}{c}\text { Source } \\
\text { Duration } \\
\text { (sec) }\end{array}$ & $\begin{array}{c}\text { Selsmic } \\
\text { Moment } \\
\times 10^{25} \\
\text { (dyne-cm) }\end{array}$ & $\begin{array}{c}\text { Fault } \\
\text { Raduus } \\
(\mathbf{k m})\end{array}$ & $\begin{array}{c}\text { Fault } \\
\text { Area } \\
\left(\mathrm{km}^{2}\right)\end{array}$ & $\begin{array}{c}\text { Dislocation } \\
(\mathrm{cm})\end{array}$ & $\begin{array}{c}\text { Stress } \\
\text { Drop } \\
\text { (bars) }\end{array}$ \\
\hline
\end{tabular}

$09 \mathrm{~h} 21 \mathrm{~m}$

\begin{tabular}{lcrrrrr} 
Cipar (1980) & 35 & 10 & 5.6 & 100.0 & 33 & 24 \\
SP53 & & & & & & \\
1st & 164 & 0.18 & 26 & 216 & 28 & 44 \\
2nd & 2.30 & 0.59 & 3.7 & 42.6 & 43 & 35 \\
& \multicolumn{6}{c}{$03 \mathrm{~h} 15 \mathrm{~m}$}
\end{tabular}

\begin{tabular}{lrrrrrr}
$\begin{array}{l}\text { SP27 } \\
\text { 1st }\end{array}$ & 1.76 & 024 & 27 & 22.4 & 36 & 56 \\
2nd & 152 & 0.12 & 23 & 167 & 24 & 43 \\
& & & & & \\
& & & & & \\
& & & & & & \\
Cipar (1980) & 4.50 & 4.0 & 113 & 4000 & 33 & 12 \\
25SP & & & & & & \\
1st & 1.00 & 0.12 & 16 & 8.0 & 49 & 126 \\
2nd & 102 & 0.27 & 16 & 84 & 107 & 276 \\
3rd & 1.66 & 0.30 & 2.7 & 222 & 45 & 51 \\
\hline
\end{tabular}

Source dimensions for the main shock and $09 \mathrm{~h} 21 \mathrm{~m}$ aftershock have been estimated by Cipar (1980) by comparing observed records to synthetics computed for a finite fault. For the $09 \mathrm{~h} 21 \mathrm{~m}$ aftershock, the combined source area of the two events inferred from the short-period records is about 65 per cent of the area obtained from long-period data (Table 8). Given the assumptions involved in both calculations, this discrepancy is probably not significant. The short-period source area for the main shock, on the other hand, is a factor of 10 smaller than the longperiod area. Allowing for the uncertainties in these results, it appears that the shortperiod radiation comes primarily from limited regions of the fault plane whereas the long-period seismograms record the overall motion of the earthquake.

The salient point of Table 8 is that the overall stress drop estimated from longperiod records, which presumably sample the whole faulting process, is consistently lower than the stress drops calculated for each individual short-period event. The 
first two events of the main shock had quite high-stress drops, but overall, the earthquake was characterized by low-stress drop. While the stress drops quoted in Table 8 must be regarded as rough estimates due to the assumptions involved, it seems clear that these earthquakes are made up of a number of episodes of highstress drop from limited regions of the fault plane superimposed on an obligato of smooth rupture.

There is a growing body of observations which suggest that massive failure at the initiation of faulting is a feature common to many shallow earthquakes. Burdick and Mellman (1976) conclude that most of the body waves radiated by the 1968 Borrego Mountain, California, earthquake came from a small patch on the fault plane which had a radius of $8 \mathrm{~km}$. The stress drop in this zone was 96 bars. Ebel (1980) concludes that the short-period seismograms of this earthquake record radiation from two regions, one of $7.7 \mathrm{~km}$ and the other of $4.0 \mathrm{~km}$ diameter, having stress drops of 436 and 366 bars, respectively. Other observations of this phenomenon have been made by Hartzell and Brune (1979) for the 1975 Horse Canyon, California, earthquake and Bache et al. (1980) for the Pocatello Valley, Idaho, shock.

\section{CONCLUSIONS}

In the preceeding sections, teleseismic short-period $P$ waves of three moderatesized, shallow earthquakes - the main shock and two aftershocks of the 1976 Friuli, Italy, sequence-have been successfully modeled in the time domain using synthetic seismograms computed for a point source in a layered medium. Source parameters such as depth, far-field time function, and seismic moment are inferred by a combination of forward modeling and waveform inversion.

The short-period $P$ waves for each earthquake were modeled using several point sources of radiation each having time durations on the order of 1 to $3 \mathrm{sec}$. Source dimensions and stress drops were estimated using a simple circular fault formulation. Each individual event inferred from the short-period records has a relatively high stress drop (35 to 276 bars) whereas the overall earthquake source derived from long-period seismograms has a lower stress drop (12 bars for the main shock, 24 bars for the $09 \mathrm{~h} 21 \mathrm{~m}$ aftershock). The individual point sources which combine to make the short-period records have source radii on the order of 2 to $4 \mathrm{~km}$, much smaller than the dimensions inferred from long-period data. For two of the earthquakes studied, the short-period moment is lower than the moment computed from longperiod records. These results suggest that the short-period events are radiated from limited, high-stress regions of the fault and that most of the fault has lower stress. The low-stress portions of the fault plane radiate energy at longer periods at which the short-period instruments are not especially sensitive.

\section{ACKNOWLEDGMENTS}

The author wishes to thank John Ebel, Jim Pechmann, Tom Heaton, Don Helmberger, and Terry Wallace for critically reading the manuscript and providıng many valuable comments. George Mellman and John Ebel generously provided their waveform inversion program. Laszlo Lenches carefully drafted the figures, Roslyn Scherr cautiously typed the manuscript, and Mary Martyak competently proofread the final draft.

This research was sponsored by the Earth Sciences Section, National Science Foundation, Grant PFR-7921769.

\section{REFERENCES}

Angenhesster, G., H. Bogel, H Gebrande, P Ge1se, P Schmidt-Thome, and W. Ze1l (1972). Recent investigations of surficial and deeper crustal structures of the eastern and southern Alps, Geologtshe Rundschau 61, 349-395 
Bache, T. C, D G. Lambert, and T G. Barker (1980). A source model for the March 28, 1975, Pocatello Valley earthquake from tıme-doman modeling of teleseismic $P$ waves, Bull. Sersm Soc. Am. 70, 405-418

Ben-Menahem, A, M Rosenman, and D G Harkrider (1970) Fast evaluation of source parameters from isolated surface wave signals, Bull Sersm Soc. Am 60, 1337-1387

Burdick, L J. and G R. Mellman (1976). Inversion of the body waves from the Borrego Mountain earthquake to the source mechanısm, Bull Seusm. Soc Am 66, 1485-1499.

Chung, W.-Y (1978) Part I Variation of selsmic source parameters and stress drop withın a descending slab as revealed from body-wave pulse width and amplitude analysis, Part II. A seismological investigation of the subduction mechanısm of aseismic ridges, $P h D$ Thesis, Calıfornia Institute of Technology, Pasadena, Cahforna

Cipar, J (1980) Teleseismic observations of the 1976 Friul, Italy, earthquake sequence, Bull. Setsm Soc $A m$ 70, 963-983

Ebel, J. (1980). Evidence for fault asperities from systematic time-domain modeling of teleseismic waveforms, $P h D$ Thesis, California Institute of Technology, Pasadena, Calıfornia

Ebel, J , L J. Burdick, and G. S. Stewart (1978) The source mechanısm of the August 7, 1966 El Golfo earthquake, Bull Seusm. Soc. Am 68, 1281-1292.

Futterman, W. I (1962) Dispersive body waves, J. Geophys Res 67, 5279-5291

Geller, R. J. (1976) Scalıng relations for earthquake source parameters and magnitudes, Bull. Setsm Soc Am 66, 1501-1523.

Hagiwara, T (1958). A note on the theory of the electro-magnetic selsmograph, Bull Earthquake Res Inst, Tokyo Univ 36, 139-164

Hartzell, S. (1980) Faulting process of the May 17, 1976 Gazli, U.S S R. earthquake, Bull Selsm Soc Am 70, 1715-1736

Hartzell, S. and J N Brune (1979). The Horse Canyon Earthquake of August 2, 1975-Two stage stress release process in a strike-slip earthquake, Bull. Setsm Soc Am. 69, 1161-1173

Haskell, N A. (1962). Crustal reflection of plane P and SV waves, J. Geophys Res 67, 4751-4767

Helmberger, D. V. (1974) Generalized ray theory for shear dislocations, Bull Sersm Soc. Am 64, 45-64

Kanamorı, H and D. L. Anderson (1975). Theoretical basis of some empirical relations in seismology, Bull. Selsm Soc. Am 65, 1073-1095.

Langston, C A. (1976). A body wave inversion of the Koyna, India earthquake of December 10, 1967 and some implications for body wave focal mechanisms, J. Geophys. Res. 81, 2517-2529

Langston, C. A. (1978). The February 9, 1971 San Fernando earthquake. a study of source finiteness in teleseismic body waves, Bull. Sersm Soc Am. 68, 1-30.

Langston, C A. and R. Butler (1976). Focal mechanism of the August 1, 1975 Orovlle earthquake, Bull. Seusm. Soc. Am 66, 1111-1120

Langston, C. A and D V Helmberger (1975). A procedure for modeling shallow dislocation sources, Geophys. J. 42, 117-130.

Mellman, G R. (1978) A method for waveform inversion of body-wave seismograms, $P h D$. Thesis, Calıforna Institute of Technology, Pasadena, California.

Savage, J C (1966) Radiation from a realıstıc model of faultıng, Bull. Setsm Soc Am. 56, 577-592

Somerville, P G, R. A. Wiggins, and R. M Ellis (1976). Time domain determination of earthquake fault parameters from short-period $P$-waves, Bull Seusm. Soc. Am. 66, 1459-1484.

Wyss, M. and T. C. Hanks (1972). The source parameters of the San Fernando earthquake from telesersmic body waves, Bull. Seusm. Soc. Am 62, 591-602

\author{
SEISMOLOGICAL LABORATORY \\ California Institute of Technology \\ Pasadena, California 91125 \\ Contribution No 3516
}

Manuscript recelved December 1, 1980 